\title{
Smartphone use and addiction during the coronavirus disease 2019 (COVID-19) pandemic: cohort study on 184 Italian children and adolescents
}

\author{
Gregorio Serra ${ }^{1 *} \mathbb{D}$, Lucia Lo Scalzo ${ }^{1}$, Mario Giuffrè ${ }^{1}$, Pietro Ferrara ${ }^{2}$ and Giovanni Corsello ${ }^{1}$
}

\begin{abstract}
Background: The lives of many children and adolescents are today increasingly influenced by new technological devices, including smartphones. The coronavirus disease 2019 (COVID-19) pandemic occurred in a time of outstanding scientific progress and global digitalization. Young people had relevant adverse psychological and behavioral effects due to the COVID-19 pandemic, mainly related to infection control measures, which led them to spend more time at home and with major use of technological tools. The goal this study proposes is to evaluate health and social outcomes of smartphone overuse among Italian children and adolescents during the COVID-19 pandemic, analyzing patterns and aims of utilization, as well as the eventual presence and degree of addiction.
\end{abstract}

Methods: This study was based on a self-report and anonymous questionnaire, which was administered to 184 Italian school-age (6-18 years) children and adolescents during the second wave of the COVID-19 pandemic. The test was electronically (email, whatsapp) explained and sent by pediatricians either directly to older children (middle and high school), or indirectly, through the help of teachers, to younger ones (primary school). All participants spontaneously and voluntarily joined the present study. The survey was made by 4 sections, and designed to know and outline modalities (frequency, patterns and aims) of smartphone use, adverse outcomes, and related parental behaviors, also in order to reveal the eventual occurrence and degree of addiction. The same information, related to the pre-epidemic period, was also investigated and analyzed.

Results: The data obtained revealed a significantly greater adhesion to the questionnaire by females, likely reflecting higher attention and interest than boys to initiatives relating to health education. Our study showed more frequent smartphone use among Italian children and adolescents during the COVID-19 pandemic, compared to the pre-epidemic period. This may be related to the social distancing measures adopted during the months under investigation. The present survey also outlined the changing patterns and aims in the use of smartphones among young people, which allowed to limit some effects of the crisis. Indeed, they were used for human connection, learning and entertainment, providing psychological and social support. Finally, it was observed a significant increase of overuse and addiction. This led to many clinical (sleep, ocular and musculoskeletal disorders),

\footnotetext{
* Correspondence: gregorio.serra@unipa.it

'Department of Health Promotion, Mother and Child Care, Internal Medicine and Medical Specialties "G. D'Alessandro", University of Palermo, Palermo, Italy

Full list of author information is available at the end of the article
}

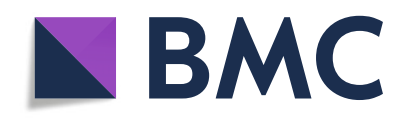

(- The Author(s). 2021 Open Access This article is licensed under a Creative Commons Attribution 4.0 International License, which permits use, sharing, adaptation, distribution and reproduction in any medium or format, as long as you give appropriate credit to the original author(s) and the source, provide a link to the Creative Commons licence, and indicate if changes were made. The images or other third party material in this article are included in the article's Creative Commons licence, unless indicated otherwise in a credit line to the material. If material is not included in the article's Creative Commons licence and your intended use is not permitted by statutory regulation or exceeds the permitted use, you will need to obtain permission directly from the copyright holder. To view a copy of this licence, visit http://creativecommons.org/licenses/by/4.0/. The Creative Commons Public Domain Dedication waiver (http://creativecommons.org/publicdomain/zero/1.0/) applies to the data made available in this article, unless otherwise stated in a credit line to the data. 
psychological (distraction, mood modification, loss of interest) and social (superficial approach to learning, isolation) unfavorable outcomes.

Conclusions: Pediatricians and health care professionals should be aware of the potential risks related to inappropriate use of smartphones. They should monitor, in cooperation with parents, possible associated adverse effects, in order to early recognize signs and symptoms suggestive, or at high risk, for addiction. They must carry out, as well, the necessary interventions to prevent and/or lower the detrimental impact of smartphone overuse on children and adolescents' health, oriented to sustain adequate physical and psychological development as well as social relationships.

Keywords: Smartphone, Addiction, COVID-19, School-age children, Italy

\section{Background}

The lives of many children and adolescents are today increasingly influenced by new technological devices and means of communication (smartphones, tablets, social network) [1]. Specifically, in recent years, smartphone use has rapidly increased worldwide. In Italy, the number of users is constantly growing, and it is estimated to reach in 2025 around 42 million subjects [2]. Its overuse may lead to clinical, psychological and social adverse outcomes [3-5]. Although smartphone addiction is not included in the latest version of the Diagnostic and Statistical Manual for Mental Disorders, research studies and social interventions were conducted to address its related unfavorable effects [6]. The coronavirus disease 2019 (COVID-19) pandemic occurred at a time of global digitalization, characterized by quick connection of people and information anywhere in the world. Children and adolescents had lower incidence and mortality rates of COVID-19 than adults [7, 8]. However, they had relevant adverse psychological and behavioral effects, especially among school-age ones, due to home confinement and other infection control measures, such as social distancing, and closure of schools and shared public spaces [9]. This led them, as well as adults, to spend more time at home and with major use of technological devices [10]. The goal this study proposes is to evaluate health outcomes and social implications of smartphone overuse among Italian children and adolescents during the COVID-19 pandemic, analyzing patterns and aims of utilization, as well as the eventual presence and degree of addiction, and comparing them with those of the preepidemic period.

\section{Methods}

\section{Study setting}

COVID-19, the acute respiratory syndrome related to the new coronavirus (SARS-CoV-2) infection, dramatically spread worldwide from China since the end of 2019. It reached Italy, first among European countries, on February 2020. The following further rapid diffusion to other continents on March 11th 2020, led the World
Health Organization (WHO) to declare a pandemic. The study took place over a 2-month period, from December 2020 to January 2021. In that time Italy, within the second wave of the pandemic, was divided into three zones - red, orange, yellow- corresponding to three different scenarios of epidemiologic risk [11]. The division of the country into three areas was based on 21 criteria, established by the Italian National Institute of Health. The main indicators included local/regional infection rates and hospital (ordinary and intensive care) occupancy, as well as other factors related to care capacity/outbreak management of the different regional health systems (i.e. availability of health care professionals, effectiveness of the contact tracing system) [12]. Specific strategies to contrast the spread of the disease were taken and tuned, based on the different risk scenarios. Where the overall risk of COVID-19 spread was increased, the movement of people and the economic and social activities were more limited according to the Decrees of the President of the Council of Ministers (DPCM), which varied on a period basis. Teaching and educational activities and services were intermittently carried out in presence for children of infant schools, primary schools and partially of lower secondary schools. For the remaining lower secondary school children and for high school adolescents, distance teaching (online) was the only modality of education which was guaranteed [13].

\section{Selection of study participants}

This study was based on a self-report and anonymous questionnaire, which was administered to Italian schoolage (6-18 years) children and adolescents during the second wave of the COVID-19 pandemic. The test was conceived and made by pediatricians of the Mother and Child Department of the University of Palermo (Sicily, Italy). Questions were created in Google Forms. They were electronically (email, whatsapp) explained in detail, together with the aims of this study, and directly sent to older children (middle and high school), or indirectly, through the help of teachers, to younger ones (primary school). The forms were addressed in Sicily and in 
regions of northern Italy (Piedmont, Lombardy). Among around three hundred questionnaires homogeneously distributed between males and females of different age groups, a total of 185 students replied and participated in the study. All participants spontaneously and voluntarily joined the present survey. Lack of partial and/or total completion of the questionnaire was the only exclusion criterion. Their answers were recorded on a web-based Google sheet form, and then analyzed.

\section{Data collection}

The questionnaire was designed to understand modalities (frequency, patterns and aims) of smartphone use, its impact (adverse effects) on everyday life, and related parental behaviors among children and adolescents, also in order to reveal the eventual occurrence and degree of addiction, before and during the COVID-19 pandemic. It was made by 4 sections.

The first section was about demographic and socioeconomic characteristics, and included the following variables: age, gender, ethnicity, school year, region of residence, family status, parents' educational level, occupation and income, age at onset of smartphone use.

The second section concerned COVID-19 related questions: family members' jobs linked to the epidemic (specific occupation), family members and/or friends infected by SARS-CoV-2 or dead due to COVID-19, degree of concern about the pandemic, implementation of preventive and infection control measures, eventual distance (online) learning and impact of the pandemic on education.

The third section included questions on frequency of smartphone use (i.e. time of smartphone use per day, time between wake up and start of use, frequency of night utilization), and about patterns and effects of their utilization before and during the pandemic, evaluated with the following items: "most frequently used functions", "aim of use", "adverse effects" and "parental attitude towards smartphone use". The most frequently used functions included: "telephone call", "social network (Instagram, Facebook)", "game”, "education", "online chat (Whatsapp)", "photos", "videos" and "music". To analyze the aims of smartphone use, we included the following items: "boredom", "habit", "pleasure", "game", "communication", "learning", "stress relief" and "adaptation to others". The answers on adverse effects included: "superficial approach to learning", "distraction", "mood modification", "loss of interest", "isolation", "sleep disturbances", "ocular alterations" and "musculoskeletal disorders". Questions on parental attitude regarding smartphone use included the following items: "surveillance", "restriction", "punishment", "permission" and "explanation". Participants gave to each of these four items a score, ranging from 1 (never) to 5 (always).
The fourth section was related to the evaluation of eventual occurrence and degree of smartphone addiction, measured by the Italian Smartphone Addiction Scale Short Version (SAS-SV) [14]. It is a well-validated specific questionnaire, which contains 10 questions including daily-life disturbance, positive anticipation, withdrawal, cyberspace-oriented relationship, overuse and tolerance (Table 1).

Participants expressed their opinion for each item over a 6-point scale, ranging from 1 (strongly disagree) to 6 (strongly agree). A different normal range is identified for males and females. Males are considered addicted if scores are higher than 31. High risk of addiction is present with scores between 22 and 31. Females are addicted if scores are higher than 33, and at high risk with scores between 22 and 33 [15].

\section{Statistical analysis}

We used R version 4.0.4 (R Foundation for Statistical Computing, Vienna, Austria) for data analysis. Simple descriptive statistics were expressed as frequency and percentage for categorical variables, mean and standard deviation (SD) for continuous variables. Paired-samples t-test was used to compare data on patterns of smartphone use in the study population, before and during the COVID-19 pandemic. A $p$ value lower than 0.05 was considered statistically significant.

\section{Results}

\section{Sociodemographic characteristics}

Of the 185 study participants, one was excluded (0.5\%) because he did not complete the questionnaire. Thus, 184 school-age children and adolescents were included. Among them, 52 (28.3\%) were male and 132 (71.7\%) female. Their mean age was $14.84 \pm 2.73$ years. The sample comprised 39 (21.2\%) children aged 6-12 years, and 145 (78.8\%) adolescents aged 13-18 years. Ten (5.4\%) attended primary school, 48 (26.1\%) lower secondary school (middle school) and 126 (68.5\%) upper secondary school (high school). All study participants were Italian. They came from 3 different regions: 167 (90.8\%) Sicily, 15 (8.1\%) Piedmont and 2 (1.1\%) Lombardy. 152 (82.6\%) belonged to urban areas, and $32(17.4 \%)$ to rural ones. One hundred seventy-two (93.5\%) lived with married parents, $12(6.5 \%)$ with only one parent, due to parental separation/divorce (7) or death (5). Seventy-one (38.6\%) mothers were graduated, 86 (46.7\%) had high school education, 26 (14.2\%) lower secondary school, and one (0.5\%) primary school. 59 (32.1\%) fathers were graduated, 88 (47.8\%) had high school education, 36 (19.6\%) lower secondary school, and one (0.5\%) primary school. One hundred participants (54.3\%) belonged to doubleincome families (employed and independent workers), $84(45.7 \%)$ to single-income ones (unemployed/ 
Table 1 Italian Smartphone Addiction Scale Short Version (modified from De Pasquale et al., 2017) [14]

\begin{tabular}{ll}
\hline 1 & Missing planned work due to smartphone use \\
3 & Having a hard time concentrating in class, while doing assignments, or while working due to smartphone use \\
4 & Feeling pain in the wrists or at the back of the neck while using a smartphone \\
5 & Will not be able to stand not having a smartphone \\
6 & Feeling impatient and fretful when I am not holding my smartphone \\
7 & Having my smartphone in my mind even when I am not using it \\
8 & I will never give up using my smartphone even when my daily life is already greatly affected by it \\
9 & Constantly checking my smartphone so as not to miss conversations between other people on WhatsApp, Facebook or Instagram \\
10 & Using my smartphone longer than I had intended \\
\hline
\end{tabular}

housewives). All respondents owned a smartphone. The average age at owning smartphone was $10.57 \pm 1.8$ years (Table 2).

\section{COVID-19 related data}

Twenty-four (13\%) participants reported a work related to the epidemic emergency for their family members, 18 of whom referring health care professions (e.g., doctors and nurses).Seventy-six (41.3\%) subjects stated that family members and/or friends were infected with SARSCoV-2. Four (2.2\%) adolescents lost a relative due to COVID-19. A total of 83 (45.1\%) respondents reported to be very concerned about the pandemic, and 98 $(53.3 \%)$ averagely worried. One hundred sixty-eight (87\%) participants had strictly implemented preventive and control measures (e.g., wash hands, wear mask, avoid public and crowded places) against the epidemic spread. Furthermore, 132 (71.7\%) children and adolescents reported that the COVID-19 pandemic affected their learning. A total of 176 (95.7\%) students followed distance learning (Table 3).

\section{Smartphone use before and during the COVID-19 pandemic}

Average time per day of smartphone use during the pandemic was higher than before: 122 (66.3\%) participants spent more than $4 \mathrm{~h}$ per day during the COVID-19 pandemic, while those before the pandemic were 30 (16.3\%). Time between wake up and start of use was lower during the pandemic, with 104 (56.5\%) subjects reporting their first use within $5 \mathrm{~min}$ after wake up, compared to 47 (25.5\%) during the pre-epidemic period. Frequency of night utilization during the pandemic was also increased than before: 103 (56\%) children and adolescents used smartphone after midnight at least 3 times per week, while those during the pre-epidemic period were 56 (30.4\%) (Table 4).

\section{Most frequently used functions}

During the COVID-19 pandemic, the participants used more frequently than before the following functions: "telephone call", "social network (Instagram, Facebook)", "game", "education", "online chat (Whatsapp)", "music" and "videos". Conversely, for "photos" a statistically significant difference was not observed (Table 5).

\section{Aim of use}

The respondents did not show a difference in the aims of use "pleasure" and "adaptation to others", before and during the COVID-19 pandemic. Conversely, they indicated as aims of use more frequently reported the following ones: "boredom", "habit", "game", "communication", "learning" and "stress relief" (Table 5).

\section{Adverse effects}

All of the following adverse effects (clinical, psychological/behavioral, social) related to smartphone use were significantly more frequently reported in the study population during the COVID-19 pandemic, compared to the pre-epidemic period: "superficial approach to learning", "distraction", "mood modification", "loss of interest", "isolation", "sleep disturbances", "ocular alterations" and "musculoskeletal disorders" (Table 5).

\section{Parental attitude towards smartphone use}

There were no statistically significant differences, during and before the COVID-19 pandemic, for the following parental attitudes: "surveillance", "restriction", "punishment" and "explanation".By converse, a "permissive" attitude was significantly more frequently observed during the pandemic (Table 5).

\section{Smartphone addiction}

Before the COVID-19 pandemic, among the 184 study participants, 58 (31.5\%) were found at high risk of addiction, and in 48 (26.1\%) addiction has been documented. During the COVID-19 pandemic, addiction was outlined 
Table 2 Sociodemographic characteristics of the study population

\begin{tabular}{|c|}
\hline Variables \\
\hline Sex \\
\hline Male \\
\hline Female \\
\hline Age (years) \\
\hline Range \\
\hline $6-12$ \\
\hline $13-18$ \\
\hline Mean \pm SD \\
\hline Educational level \\
\hline Primary school \\
\hline Middle school \\
\hline High school \\
\hline Region of residence \\
\hline Sicily \\
\hline Piedmont \\
\hline Lombardy \\
\hline Area of origin \\
\hline Urban \\
\hline Rural \\
\hline Family status \\
\hline Married parents \\
\hline Separated/divorced parents \\
\hline Widow parent \\
\hline Parents' educational level \\
\hline Mother \\
\hline Primary school \\
\hline Middle school \\
\hline High school \\
\hline Graduation \\
\hline
\end{tabular}

\section{Father}

Primary school

Middle school

High school

Graduation

Family income

Double-income

Single-income

\section{Age at owning smartphone (years)}

Range

Mean \pm SD

$S D$ standard deviation
Table 3 COVID-19 related information

\begin{tabular}{|c|c|}
\hline Variables & N (\%) \\
\hline \multicolumn{2}{|c|}{ Family members with jobs related to the epidemic } \\
\hline Both parents & $6(3.2 \%)$ \\
\hline Father & $11(6 \%)$ \\
\hline Mother & $7(3.8 \%)$ \\
\hline None & $160(87 \%)$ \\
\hline \multicolumn{2}{|c|}{ Family members' work related to the epidemic emergency } \\
\hline Doctor & $7(29.2 \%)$ \\
\hline Nurse & $3(12.5 \%)$ \\
\hline Other health care professional & $8(33.3 \%)$ \\
\hline Different from health care professional & $6(25 \%)$ \\
\hline \multicolumn{2}{|c|}{ Family members and/or friends affected by COVID-19 } \\
\hline Yes & $76(41.3 \%)$ \\
\hline No & $108(58.7 \%)$ \\
\hline \multicolumn{2}{|l|}{ Relative died for COVID-19 } \\
\hline Yes & $4(2.2 \%)$ \\
\hline No & $180(97.8 \%)$ \\
\hline \multicolumn{2}{|l|}{ Degree of concern about the pandemic } \\
\hline Very concerned & $83(45.1 \%)$ \\
\hline Average & $98(53.3 \%)$ \\
\hline Not concerned & $3(1.6 \%)$ \\
\hline \multicolumn{2}{|c|}{ Implementation of infection prevention and control measures } \\
\hline Strictly enforced & $168(91.3 \%)$ \\
\hline Sometimes & $13(7.1 \%)$ \\
\hline Never & $3(1.6 \%)$ \\
\hline \multicolumn{2}{|l|}{ Learning problems due to the pandemic } \\
\hline Yes & $132(71.7 \%)$ \\
\hline No & $52(28.3 \%)$ \\
\hline \multicolumn{2}{|l|}{ Distance learning } \\
\hline Yes & $176(95.7 \%)$ \\
\hline No & $8(4.3 \%)$ \\
\hline
\end{tabular}

$1(0.5 \%)$

$36(19.6 \%)$

$88(47.8 \%)$

$59(32.1 \%)$

$100(54.3 \%)$

$84(45.7 \%)$

6-15

$10.57 \pm 1.8$

in $86(46.7 \%)$ participants, while those at high risk were 50 (27.2\%) (Fig. 1).

\section{Discussion}

Although the present survey was equally proposed to subjects of both genders, a significantly greater adhesion by females was however observed. This may reflect a higher degree of attention and interest of girls, than boys, to initiatives (including those realized at school) relating to health education. Furthermore, although distributed to subjects belonging to different Italian regions, a wider participation of Sicilian subjects occurred for reasons likely related to direct knowledge of the pediatricians promoting the study. Despite the limitations of an inhomogeneous representation of the population analyzed (either in gender or age or geographic origin), 
Table 4 Frequency of smartphone use before and during the COVID-19 pandemic

\begin{tabular}{|c|c|c|}
\hline Frequency of smartphone use & Before the pandemic $\mathrm{N}(\%)$ & During the pandemic $\mathrm{N}(\%)$ \\
\hline \multicolumn{3}{|l|}{ Time per day } \\
\hline$<1 \mathrm{~h}$ & $13(7.1 \%)$ & $3(1.6 \%)$ \\
\hline$\geq 1 \mathrm{~h}<2 \mathrm{~h}$ & $76(41.3 \%)$ & $10(5.4 \%)$ \\
\hline$\geq 2 h<4 h$ & $65(35.3 \%)$ & $49(26.6 \%)$ \\
\hline$\geq 4 \mathrm{~h}$ & $30(16.3 \%)$ & $122(66.3 \%)$ \\
\hline \multicolumn{3}{|c|}{ Time between wake up and start of use } \\
\hline $5 \mathrm{~min}$ & $47(25.5 \%)$ & $104(56.5 \%)$ \\
\hline$>5 \min \leq 30 \min$ & $87(47.3 \%)$ & $53(28.8 \%)$ \\
\hline$>30 \min \leq 60 \min$ & $26(14.1 \%)$ & $11(6 \%)$ \\
\hline$>60 \min$ & $24(13.1 \%)$ & $16(8.7 \%)$ \\
\hline \multicolumn{3}{|l|}{ Frequency of night utilization } \\
\hline Never & $53(28.8 \%)$ & $31(16.8 \%)$ \\
\hline Once per week & $32(17.4 \%)$ & $15(8.2 \%)$ \\
\hline Twice per week & $43(23.4 \%)$ & $35(19 \%)$ \\
\hline$\geq 3$ times per week & $56(30.4 \%)$ & $103(56 \%)$ \\
\hline
\end{tabular}

however, the validity of the results obtained may not be affected, also in light of the overlapping conditions of the different Italian regions, in terms of mortality/morbidity rates due to the COVID-19 pandemic, as well as of economic, social and school settings, during the period under investigation. Our study, indeed, showed that, during the pandemic, children and adolescents significantly increased their average daily smartphone use. This may be explained by the wide and multiple role played by smartphones during the epidemic. This is unsurprising, also considering the potential tasks of smartphones as source of communication, information and entertainment [16]. They, indeed, combine the services provided by the web and those of the mobile phone, allowing distance communication and information. At a time of social separation, as that observed in present study, people relied on such useful aspects more than in normal circumstances. Actually, during the COVID-19 pandemic people's behaviors (and also those of children and adolescents) changed, and partially limited the effects of the crisis [17]. Indeed, smartphones may be used for many purposes, like human connection, learning, and entertainment, and they thus provided psychological and social support. Our study documented an increase, during the pandemic, of smartphone functions like telephone calls, videos, online chats, and social network. This may reflect the lack of physical relationships and contacts with relatives (especially grandparents) and/or friends experienced in this period by children and adolescents, due to the strict social distancing measures adopted [18]. Then, our findings highlighted how during the pandemic communication devices ceased to be only a support for human relationships, and almost entirely replaced face-to-face interactions, becoming the main channel for social connections, especially among young people. Moreover, smartphones provided to children and adolescents the opportunity to continue schooling. Indeed, the partial closure of schools imposed during the pandemic forced teachers to create and use online learning systems [19]. This had pedagogical/psychological consequences in students' life and families' organization, due to the need of adequate technological skills, new learning strategies, as well as availability of digital devices and fast connectivity [20, 21]. Online learning led to an increase of the screen time, resulting in turn to a greater possibility of students' distraction by social media or games [22]. Furthermore, increased digitalization widened the "educational gap" among families. Specifically, poorest children were the most penalized, as they do not likely have a quiet place in their home for their studies, or their own digital devices to access online education [23]. The majority of children and adolescents of present survey, indeed, reported that COVID-19 pandemic affected their learning: online education quality was perceived as lower than in presence one, and pandemic-related anxiety had a negative impact on students' academic performances [17, 24]. Owing to the temporary and partial closure of educational institutions and suspension of related activities, as well as to the prohibition of shared public spaces, school-age children and adolescents used smartphones more frequently also for entertainment. Indeed, our survey confirmed that their use for recreational purpose became more frequent during the pandemic. The occurrence of infections and/or diseases due to SARS-CoV-2 among family members and/or friends contributed to increase the 
Table 5 Patterns of smartphone use and related adverse effects and parental behavior, before and during the COVID-19 pandemic

\begin{tabular}{|c|c|c|c|c|}
\hline Items & Range & Before the pandemic Mean \pm SD & During the pandemic Mean \pm SD & $P$ value \\
\hline \multicolumn{5}{|l|}{ Most frequently used functions } \\
\hline Telephone calls & $1-5$ & $3.33 \pm 1.09$ & $3.80 \pm 1.16$ & $<0.001^{\mathrm{a}}$ \\
\hline Social network (Instagram, Facebook, etc.) & $1-5$ & $3.81 \pm 1.27$ & $4.07 \pm 1.20$ & $<0.001^{\mathrm{a}}$ \\
\hline Game & $1-5$ & $2.57 \pm 1.20$ & $2.85 \pm 1.43$ & $0.001^{a}$ \\
\hline Education & $1-5$ & $2.87 \pm 1.26$ & $4.13 \pm 1.05$ & $<0.001^{\mathrm{a}}$ \\
\hline Online chat (Whatsapp, etc.) & $1-5$ & $3.32 \pm 1.53$ & $3.61 \pm 1.63$ & $<0.001^{a}$ \\
\hline Photos & $1-5$ & $3.29 \pm 1.21$ & $3.15 \pm 1.24$ & 0.1 \\
\hline Videos & $1-5$ & $3.43 \pm 1.20$ & $3.70 \pm 1.31$ & $0.002^{\mathrm{a}}$ \\
\hline Music & $1-5$ & $3.79 \pm 1.22$ & $3.94 \pm 1.25$ & $0.043^{\mathrm{a}}$ \\
\hline \multicolumn{5}{|l|}{ Aim of use } \\
\hline Boredom & $1-5$ & $3.32 \pm 1.10$ & $3.99 \pm 1.29$ & $<0.001^{\mathrm{a}}$ \\
\hline Habit & $1-5$ & $3.32 \pm 1.12$ & $3.65 \pm 1.24$ & $<0.001^{\mathrm{a}}$ \\
\hline Pleasure & $1-5$ & $3.47 \pm 1.10$ & $3.59 \pm 1.20$ & 0.17 \\
\hline Game & $1-5$ & $2.55 \pm 1.28$ & $2.82 \pm 1.48$ & $0.001^{\mathrm{a}}$ \\
\hline Communication & $1-5$ & $4.21 \pm 0.93$ & $4.53 \pm 0.80$ & $<0.001^{\mathrm{a}}$ \\
\hline Learning & $1-5$ & $2.99 \pm 1.09$ & $4.16 \pm 1.03$ & $<0.001^{\mathrm{a}}$ \\
\hline Stress relief & $1-5$ & $2.95 \pm 1.33$ & $3.34 \pm 1.39$ & $<0.001^{a}$ \\
\hline Adaptation to others & $1-5$ & $2.37 \pm 1.23$ & $2.52 \pm 1.40$ & 0.082 \\
\hline \multicolumn{5}{|l|}{ Adverse effects } \\
\hline Superficial approach to learning & $1-5$ & $2.01 \pm 1.04$ & $2.63 \pm 1.34$ & $<0.001^{\mathrm{a}}$ \\
\hline Distraction & $1-5$ & $2.80 \pm 1.06$ & $3.32 \pm 1.33$ & $<0.001^{\mathrm{a}}$ \\
\hline Mood modification & $1-5$ & $2.23 \pm 1.13$ & $2.85 \pm 1.44$ & $<0.001^{\mathrm{a}}$ \\
\hline Loss of interest & $1-5$ & $2.21 \pm 1.10$ & $2.80 \pm 1.39$ & $<0.001^{\mathrm{a}}$ \\
\hline Isolation & $1-5$ & $1.94 \pm 1.09$ & $2.57 \pm 1.48$ & $<0.001^{\mathrm{a}}$ \\
\hline Sleep disturbances & $1-5$ & $2.29 \pm 1.29$ & $2.88 \pm 1.35$ & $<0.001^{\mathrm{a}}$ \\
\hline Ocular alterations & $1-5$ & $1.94 \pm 1.07$ & $2.78 \pm 1.51$ & $<0.001^{\mathrm{a}}$ \\
\hline Musculoskeletal disorders & $1-5$ & $1.83 \pm 1.07$ & $2.74 \pm 1.54$ & $<0.001^{a}$ \\
\hline \multicolumn{5}{|l|}{ Parental attitude } \\
\hline Surveillance & $1-5$ & $2.61 \pm 1.29$ & $2.52 \pm 1.36$ & 0.178 \\
\hline Restriction & $1-5$ & $2.31 \pm 1.26$ & $2.32 \pm 1.33$ & 0.898 \\
\hline Punishment & $1-5$ & $2.08 \pm 1.18$ & $1.98 \pm 1.29$ & 0.0972 \\
\hline Permission & $1-5$ & $3.17 \pm 1.14$ & $3.43 \pm 1.23$ & $<0.001^{\mathrm{a}}$ \\
\hline Explanation & $1-5$ & $3.59 \pm 1.22$ & $3.70 \pm 1.26$ & 0.1 \\
\hline
\end{tabular}

SD standard deviation

a Statistically significant difference comparing the COVID-19 pandemic with the pre-epidemic period

anxiety levels in children and adolescents, which were related to their variable degree of awareness on risks and consequences of the pandemic [25]. Then, they reported that smartphones allowed to contain negative emotions, stress, sense of isolation and boredom, enabling to avoid, even temporarily, the difficult reality lived during the COVID-19 pandemic and to provide psychological support through different modalities. Specifically, games helped to feel them better and enhance self control, and likewise listening music gave relief from the epidemicrelated stressful events [26, 27]. However, by converse, smartphone addiction became more frequent in comparison with the pre-epidemic period. Smartphone overuse may have many negative effects [28, 29]. It may cause cyberbullying, hikikomori, and different neuropsychological and social problems, such as depression, eating and anxiety disorders, low self-confidence, stress, insecurity and solitude, which adversely affect children's and adolescents' development and construction of identity [30-34]. School performances may also be negatively influenced by inappropriate use of smartphones, which may lead young people to spend their time 


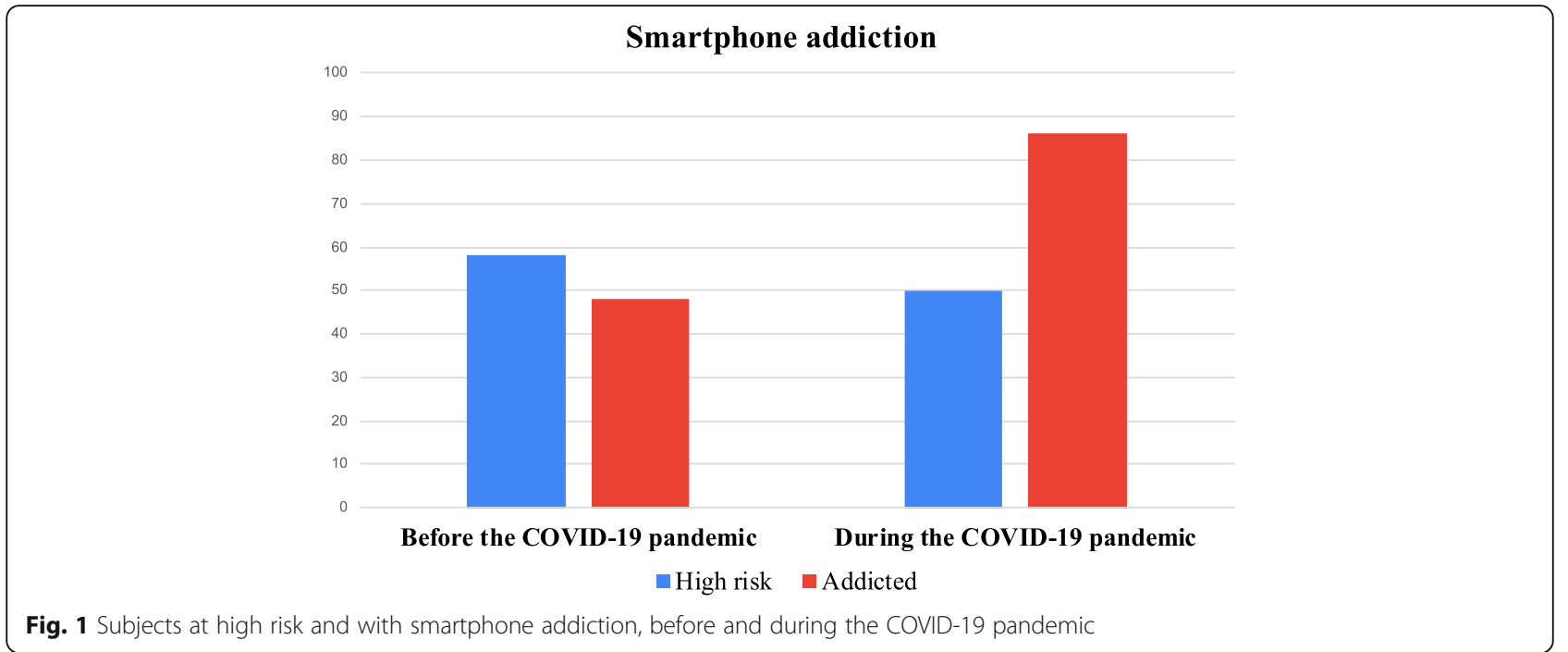

unproductively, to be less concentrated and to have a more superficial approach to learning [33, 35]. Smartphone overuse may also lead to adverse clinical outcomes, as observed in our study [36]. Indeed, during the COVID-19 pandemic our children and adolescents had sleep disturbances, ocular alterations and musculoskeletal disorders more frequently than before. Pain on neck, shoulders, wrists and fingers are the musculoskeletal disorders associated to smartphone overuse more frequently reported [37]. They may be influenced by many factors, including smartphone display size, number of messages sent, daily hours spent in front of the screen, and not physiological posture during smartphone use [38]. Their inadequate utilization may also result in ocular problems, such as dry eye disease, irritation and fatigue, burning sensation, conjunctival injection, decreased visual acuity, strain, macular degeneration and acute acquired comitant esotropia [39, 40]. These clinical symptoms may improve limiting smartphone use. This latter is frequent during bed-time among children and adolescents. This is in agreement with our study, in which a major use after midnight at least 3 times per week was observed during the pandemic. The pre-sleep smartphone use may interfere with both sleep duration and quality, and this was reported also in our study [41, 42]. However, sleep disturbances may also be associated with changed sleep-wake habits, which may have independently occurred during the COVID-19 pandemic among children and adolescents.

Finally, parents faced challenging difficulties during the pandemic in the control of their children's screen time. This was partly likely due to their attempts in finding a complex balance between personal and working life, and family responsibilities [43]. Indeed, in regard to this, a greater parental permissive attitude towards smartphone use was observed, which may have contributed to its major frequency of use during the period under investigation. Parents should set up rules to limit and appropriately use screen time, and oriented to increasingly find moments for effective interactions with their children $[44,45]$. This may be crucial for the creation of their emotional and psychological bases, necessary to ensure adequate growth and development.

\section{Conclusions}

Our study showed more frequent smartphone use among Italian children and adolescents during the COVID-19 pandemic, compared to the pre-epidemic period. This may be likely related to the social distancing measures adopted during the months under investigation. The present survey interestingly revealed the changing patterns and aims in the use of smartphones among young people, which allowed to limit some effects of the crisis. Indeed, they were exploited for many purposes such as human connection, learning and entertainment, providing psychological and social support. In the meantime, it was observed a significant increase of overuse and addiction. This led to many unfavorable clinical (sleep, ocular and musculoskeletal disorders), psychological (distraction, mood modification, loss of interest) and social (superficial approach to learning, isolation) outcomes. Pediatricians and health care professionals should be aware of such potential risks related to inappropriate use of smartphones. They should monitor, in cooperation with parents, possible associated adverse effects, in order to early recognize signs and symptoms suggestive, or at high risk, for addiction [46-48]. They must realize, as well, the necessary interventions to prevent and/or lower the detrimental impact of smartphone overuse on children and adolescents' health, oriented to sustain adequate physical and psychological development as well as social relationships. 


\section{Abbreviations}

SARS-CoV-2: severe acute respiratory syndrome coronavirus 2; COVID19: coronavirus disease 2019; DPCM: Decree of the President of the Council of Ministers; SAS-SV: Smartphone Addiction Scale Short Version; SD: standard deviation; WHO: World Health Organization

\section{Acknowledgements}

Not applicable.

\section{Authors' contributions}

GS drafted the manuscript. LLS collected data, performed statistical analysis, and drafted the first version of the manuscript. MG and PF revised the paper. GC conceived the study and gave final approval of the version to be submitted. All authors read and approved the manuscript as submitted.

\section{Funding}

No funding was granted for this research.

\section{Availability of data and materials}

The datasets used and analyzed during the current study are available from the corresponding author on reasonable request.

\section{Declarations}

\section{Ethics approval and consent to participate}

The study was approved by the Mother and Child Department of the University of Palermo (Palermo, Italy). All procedures performed in this report were in accordance with the ethical standards of the institutional and national research committee, and with the 1964 Helsinki declaration and its later amendments, or comparable ethical standards.

\section{Consent for publication}

Not applicable.

\section{Competing interests}

The authors declare that they have no competing interests.

\section{Author details}

'Department of Health Promotion, Mother and Child Care, Internal Medicine and Medical Specialties "G. D'Alessandro", University of Palermo, Palermo, Italy. ${ }^{2}$ Unit of Pediatrics, Campus Bio-Medico University, Rome, Italy.

\section{Received: 3 May 2021 Accepted: 4 June 2021}

Published online: 02 July 2021

\section{References}

1. Dinleyici M, Carman KB, Ozturk E, Sahin-Dagli F. Media Use by children, and Parents' views on Children's media usage. Interact J Med Res. 2016;5(2):e18. https://doi.org/10.2196/ijmr.5668.

2. Forecast of smartphone users in Italy from 2017 to 2025 (in millions). Statista 2021. www.statista.com.

3. Domoff SE, Borgen AL, Foley RP, Maffett A. Excessive use of mobile devices and children's physical health. Hum Behav Emerg Tech. 2019;1(2):169-75. https://doi.org/10.1002/hbe2.145.

4. Mobile TS, Use P, Health M. A review of the research that takes a psychological perspective on exposure. Int J Environ Res Public Health. 2018;15(12):2692

5. $\mathrm{hm}$ J. Social implications of children's smartphone addiction: the role of support networks and social engagement. J Behav Addict. 2018;7(2):473-81. https://doi.org/10.1556/2006.7.2018.48

6. Ting $\mathrm{CH}$, Chen YY. Chapter 8 - smartphone addiction. In: Essau CA, Delfabbro P, editors. Practical resources for the mental Health professional. San Diego: Academic Press; 2020. p. 215-40.

7. Ma H, Hu J, Tian J, Zhou X, Li H, Laws MT, et al. A single-center, retrospective study of COVID-19 features in children: a descriptive investigation. BMC Med. 2020;18(1):123. https://doi.org/10.1186/s12916-02001596-9.

8. Ludvigsson JF. Systematic review of COVID-19 in children shows milder cases and a better prognosis than adults. Acta Paediatr. 2020;109(6):108895. https://doi.org/10.1111/apa.15270
9. Singh S, Roy D, Sinha K, Parveen S, Sharma G, Joshi G. Impact of COVID-19 and lockdown on mental health of children and adolescents: a narrative review with recommendations. Psychiatry Res. 2020;293:113429. https://doi. org/10.1016/j.psychres.2020.113429.

10. Montag C, Elhai JD. Discussing digital technology overuse in children and adolescents during the COVID-19 pandemic and beyond: on the importance of considering affective neuroscience theory. Addict Behav Rep. 2020;12:100313. https://doi.org/10.1016/j.abrep.2020.100313.

11. Covid-19, situazione in Italia. www.salute.gov.it.

12. Prevenzione e risposta a COVID-19: evoluzione della strategia e pianificazione nella fase di transizione per il periodo autunno-invernale. Roma: Ministero della Salute, Istituto Superiore di Sanità; 2020. www.iss.it

13. Covid 19, the Government's new Dpcm to counter the spread of the virus on the national territory. www.salute.gov.it.

14. De Pasquale C, Sciacca F, Hichy Z. Italian validation of smartphone addiction scale short version for adolescents and Young adults (SAS-SV). Psychology. 2017:08(10):1513-8. https://doi.org/10.4236/psych.2017.810100.

15. Kwon M, Kim DJ, Cho H, Yang S. The smartphone addiction scale: development and validation of a short version for adolescents. PLoS One. 2013;8(12):e83558. https://doi.org/10.1371/journal.pone.0083558.

16. Drouin M, McDaniel BT, Pater J, Toscos T. How parents and their children used social media and Technology at the Beginning of the COVID-19 pandemic and associations with anxiety. Cyberpsychol Behav Soc Netw. 2020;23(11):727-36. https://doi.org/10.1089/cyber.2020.0284

17. Dong H, Yang F, Lu X, Hao W. Internet addiction and related psychological factors among children and adolescents in China during the coronavirus disease 2019 (COVID-19) epidemic. Front Psychiatry. 2020;11:00751. https:// doi.org/10.3389/fpsyt.2020.00751.

18. David ME, Roberts JA. Smartphone Use during the COVID-19 pandemic: social versus physical distancing. Int J Environ Res Public Health. 2021;18(3): 1034. https://doi.org/10.3390/ijerph18031034.

19. Viner RM, Russell SJ, Croker H, Packer J, Ward J, Stansfield C, et al. Schoo closure and management practices during coronavirus outbreaks including COVID-19: a rapid systematic review. Lancet Child Adolesc Health. 2020:4(5): 397-404. https://doi.org/10.1016/S2352-4642(20)30095-X.

20. Ghosh R, Dubey MJ, Chatterjee S, Dubey S. Impact of COVID -19 on children: special focus on the psychosocial aspect. Minerva Pediatr. 2020; 72(3):226-35. https://doi.org/10.23736/S0026-4946.20.05887-9.

21. Ferri F, Grifoni P, Guzzo T. Online learning and emergency remote teaching: opportunities and challenges in emergency situations. Societies. 2020;10(4): 86. https://doi.org/10.3390/soc10040086

22. Dontre AJ. The influence of technology on academic distraction: a review. Hum Behav Emerg Tech. 2020:1-12.

23. United Nations. Policy brief: education during COVID-19 and beyond. 2020. https://www.un.org/development/desa/dspd/wpcontent/uploads/sites/22/2 020/08/sg_policy_brief_covid-19_and_education_august_2020.pdf.

24. Ward M, Peters G, Shelley K. Student and faculty perceptions of the quality of online learning experiences. Int Review Research Open Distributed Learning. 2010;11(3):57-77. https://doi.org/10.19173/irrodl.v11i3.867.

25. Duan $L$, Shao $X$, Wang $Y$, Huang $Y$, Miao J, Yang $X$, et al. An investigation of mental health status of children and adolescents in China during the outbreak of COVID-19. J Affect Disord. 2020 Oct 1;275:112-8. https://doi. org/10.1016/j.jad.2020.06.029.

26. Baranowski T, Blumberg F, Buday R, DeSmet A, Fiellin LE, Green CS, et al. Games for Health for children-current status and needed research. Games Health J. 2016;5(1):1-12. https://doi.org/10.1089/g4h.2015.0026.

27. Stewart J, Garrido S, Hense C, McFerran K. Music Use for mood regulation: self-awareness and conscious listening choices in Young people with tendencies to depression. Front Psychol. 2019;10:1199. https://doi.org/10.33 89/fpsyg.2019.01199.

28. Reid Chassiakos YL, Radesky J, Christakis D, Moreno MA, Cross C; COUNCIL ON COMMUNICATIONS AND MEDIA. Children and adolescents and digital media. Pediatrics. 2016 Nov;138(5):e20162593, DOl: https://doi.org/10.1542/ peds.2016-2593.

29. Ferrara P, Corsello G, lanniello F, Sbordone A, Ehrich J, Giardino I, PettoelloMantovani M. Internet Addiction: Starting the Debate on Health and WellBeing of Children Overexposed to Digital Media. J Pediatr. 2017 Dec;191: 280-281.e1.

30. Uhls YT, Ellison NB, Subrahmanyam K. Benefits and costs of social Media in Adolescence. Pediatrics. 2017:140(Supplement 2):S67-70. https://doi.org/10.1 542/peds.2016-1758E. 
31. Liu M, Wu L, Yao S. Dose-response association of screen time-based sedentary behavior in children and adolescents and depression: a metaanalysis of observational studies. Br J Sports Med. 2016;50(20):1252-8. https://doi.org/10.1136/bjsports-2015-095084.

32. Ferrara P, Franceschini G, Corsello G, Mestrovic J, Giardino I, Sacco M, et al. The hikikomori phenomenon of social withdrawal: an emerging condition involving Youth's mental Health and social participation. J Pediatr. 2020 Oct; 225:286-8. https://doi.org/10.1016/j.jpeds.2020.06.089.

33. Rogaten J, Moneta GB, Spada MM. Academic performance as a function of approaches to studying and affect in studying. J Happiness Stud. 2013;14(6): 1751-63. https://doi.org/10.1007/s10902-012-9408-5.

34. Ferrara P, Franceschini G, Corsello G, Mestrovic J, Giardino I, Vural M, Pop TL, Namazova-Baranova L, Pettoello-Mantovani M. The Dark Side of the Web-A Risk for Children and Adolescents Challenged by Isolation during the Novel Coronavirus 2019 Pandemic. J Pediatr. 2021 Jan:228:324-325.e2.

35. Lopez-Fernandez O, Kuss DJ, Romo L, Morvan Y, Kern L, Graziani P, et al. Self-reported dependence on mobile phones in young adults: a European cross-cultural empirical survey. J Behav Addict. 2017;6(2):168-77. https://doi. org/10.1556/2006.6.2017.020.

36. Ratan ZA, Zaman SB, Islam SMS, Hosseinzadeh H. Smartphone overuse: a hidden crisis in COVID-19. Health Policy Technol. 2021;10(1):21-2. https:// doi.org/10.1016/j.hlpt.2021.01.002

37. Kim HJ, Kim JS. The relationship between smartphone use and subjective musculoskeletal symptoms and university students. J Phys Ther Sci. 2015; 27(3):575-9. https://doi.org/10.1589/jpts.27.575.

38. Lee JH, Seo KC. The comparison of cervical repositioning errors according to smartphone addiction grades. J Phys Ther Sci. 2014;26(4):595-8. https:// doi.org/10.1589/jpts.26.595.

39. Bergqvist UO, Knave BG. Eye discomfort and work with visual display terminals. Scand J Work Environ Health. 1994;20(1):27-33. https://doi.org/10. 5271/sjweh.1432.

40. Lee HS, Park SW, Heo H. Acute acquired comitant esotropia related to excessive smartphone use. BMC Ophthalmol. 2016;16(1):37. https://doi.org/1 0.1186/s12886-016-0213-5.

41. Lemola S, Perkinson-Gloor N, Brand S, Dewald-Kaufmann JF, Grob A. Adolescents' electronic media use at night, sleep disturbance, and depressive symptoms in the smartphone age. J Youth Adolescence. 2015; 44(2):405-18. https://doi.org/10.1007/s10964-014-0176-X.

42. Lanaj K, Johnson RE, Barnes CM. Beginning the workday yet already depleted? Consequences of late-night smartphone use and sleep. Organ Behav Hum Decis Process. 2014;124(1):11-23. https://doi.org/10.1016/j.obhdp.2014.01.001.

43. Ozturk Eyimaya A, Yalçin IA. Relationship between parenting practices and Children's screen time during the COVID-19 pandemic in Turkey. J Pediatr Nurs. 2021;56:24-9. https://doi.org/10.1016/.jpedn.2020.10.002

44. Bozzola E, Spina G, Ruggiero M, Vecchio D, Caruso C, Bozzola M, et al. Media use during adolescence: the recommendations of the Italian pediatric society. Ital J Pediatr. 2019;45(1):149. https://doi.org/10.1186/s13052-019-0725-8.

45. Bozzola E, Spina G, Ruggiero M, Memo L, Agostiniani R, Bozzola M, et al. Media devices in pre-school children: the recommendations of the Italian pediatric society. Ital J Pediatr. 2018 Jun 14;44(1):69. https://doi.org/10.1186/ s13052-018-0508-7.

46. Serra $G$, Memo L, Coscia A, Giuffrè M, luculano $A$, Lanna $M$, Valentini $D$, Contardi A, Filippeschi S, Frusca T, Mosca F, Ramenghi LA, Romano C, Scopinaro A, Villani A, Zampino G, and Corsello G, on behalf of their respective Scientific Societies and Parents' Associations. Recommendations for neonatologists and pediatricians working in first level birthing centers on the first communication of genetic disease and malformation syndrome diagnosis: consensus issued by 6 Italian scientific societies and 4 parents' associations. Ital J Pediatr 2021:47:94.

47. Spina G, Bozzola E, Ferrara P, Zamperini N, Marino F, Caruso C, et al. Children and Adolescent's perception of media device Use consequences. Int J Environ Res Public Health. 2021;18(6):3048. https://doi.org/10.3390/ijerph18063048.

48. Serra G, Corsello G, Antona V, D'Alessandro MM, Cassata N, Cimador M, et al. Autosomal recessive polycystic kidney disease: case report of a newborn with rare PKHD1 mutation, rapid renal enlargement and early fatal outcome. Ital J Pediatr. 2020;46(1):154. https://doi.org/10.1186/s13052-020-00922-4.

\section{Publisher's Note}

Springer Nature remains neutral with regard to jurisdictional claims in published maps and institutional affiliations.

\section{Ready to submit your research? Choose BMC and benefit from}

- fast, convenient online submission

- thorough peer review by experienced researchers in your field

- rapid publication on acceptance

- support for research data, including large and complex data types

- gold Open Access which fosters wider collaboration and increased citations

- maximum visibility for your research: over $100 \mathrm{M}$ website views per year

At BMC, research is always in progress.

Learn more biomedcentral.com/submissions 